\title{
ECONOMIC RENTABILITY OF INTRODUCING DVB-T2 HEVC SYSTEM OF TERRESTRIAL TELEVISION BROAdCASTING IN GERMANY AND CROATIA
}

\section{FRAN GALETIC}

Abstract: Germany and Croatia are among first European countries that have adopted the strategy of switching from DVB-T h.264 system to DVB-T2 h.265 (HEVC) system of broadcasting for terrestrial television. The newer $h .265$ system has better performance compared to previously h.264 especially in terms of efficiency of transmitting. On a single frequency, h.265 enables much more data flow, which means more channels and/or better quality of transmitting. This paper investigates the rentability of such transition and compares Germany as s big and Croatia as a small country. The aim of the analysis is to detect whether these two countries have the economic background for such a technological change and to compare this having in mind the difference of capacities necessary for terrestrial transmission.

Key words: terrestrial television, DVB-T, DVB-T2, HEVC, Germany, Croatia
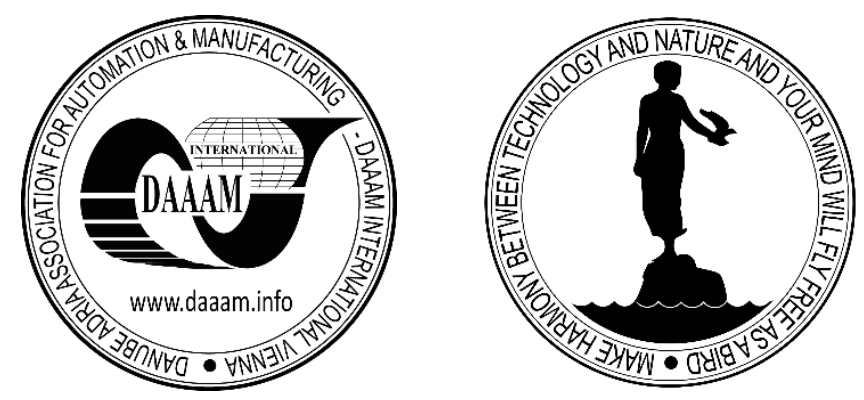

Authors' data: Fran Galetic, Faculty of Economics and Business, University of Zagreb, Trg J.F. Kennedyja 6, 10000 Zagreb, HR, fgaletic@efzg.hr

This Publication has to be referred as: Galetic, F[ran] (2020). Economic Rentability of Introducing DVB-T2 HEVC System of Terrestrial Television Broadcasting in Germany and Croatia, Chapter 17 in DAAAM International Scientific Book 2020, pp.207-216, B. Katalinic (Ed.), Published by DAAAM International, ISBN 978-3902734-27-3, ISSN 1726-9687, Vienna, Austria

DOI: $10.2507 /$ daaam.scibook.2020.17 
Galetic, F.: Economic Rentability of Introducing DVB-T2 HEVC System of Terrest...

\section{Introduction}

The most significant switch in television was the switch from analogue to digital broadcasting, which occurred at the beginning of the 21st century in most European countries. Analogue television is the original television technology, using analogue signals for transmitting television signal. The most widely known characteristic of analogue signal is that when it gets week, it becomes snowy. This is not possible in digital television, where the picture with too week signal will not be displayed at all. All broadcasting systems used analogue television before starting digital television. There are still some countries using analogue television in terrestrial broadcasting, such as Bosnia and Herzegovina.

Digital television was considered an innovative advancement and represented the first significant evolution in television technology since colour television in the 1950s [1]. Digital television provides better quality, sharper picture and more channels on a single frequency. Digital television can be broadcasted in standard definition (SD) or in high definition (HD). SDTV is usually transmitted in resolution 720x576, while HDTV is using 1920x1080 resolution. HDTV in this case has 5 times more pixels than SDTV $(2,073,600$ compared to 414,720$)$.

After most European countries have switched to digital signal in terrestrial transmitting (but also in satellite and cable television), a new standard called DVB-T2 started to emerge. Especially the one based on h.265 system, known under the name HEVC (High Efficiency Video Coding). First two countries that started transition to the new DVB-T2 HEVC system are Germany and Croatia.

\section{Literature overview}

In scientific literature there are many research about technology used for transmitting television signal, in satellite, terrestrial, cable or IPTV way. Here are presented some of these researches. They are presented in a chronological order, from the oldest one.

Meron [2] describes the next generation solution for both SDTV and HDTV distribution system. It is based on the new emerging DVB-S2 Standard, which enables a much more efficient transmission of digital video in current satellite transponders. The new technology dramatically improves utilization of the available satellite bandwidth which will enable increased programming capacity, increased geographical coverage of the satellite footprint (more customers) and accommodate future requirements for high definition TV (HDTV).

Europe was transitioning to digital terrestrial television in 2000s and is aimed to replace all analogue infrastructures by 2012 . Besides replacing all broadcasting networks in Europe, the transition requires updating household televisions and antennas. As with any major change, public administrations must keep citizens informed and provide support, especially when dealing with a communication medium expected to support a 
new portfolio of services and information. State-of-the-art technologies enable universal coverage in locations where television services are currently unavailable. Iglesias and Sabucedo [3] evaluate the transition to digital television in several European regions and analyse novel approaches and solutions to achieving universal access to digital television and citizen awareness.

In 2012 Ireland switched off its analogue spectrum marking a crucial juncture in its transition to a fully digital television system. Murphy [4] traces the long trajectory of Ireland's transition to digital television and evaluate the state's policy performance in the much-changed context of digital media governance. In Ireland the signal policy failure has been in relation to the late launch and compromised model of digital terrestrial television (DTT).

Brevini and Fanucci [5] aim at unveiling the difficult transition to digital terrestrial television (DTT) in Italy. The findings indicate that Italian DTT policies are deeply rooted within their national context and that Italian policy-makers failed to secure a solution to the abiding lack of pluralism of the Italian broadcasting market. During the transitory period, the Digital Broadcasting Act of 2001 gave the two main broadcasters - RAI and Mediaset - an unfair advantage in experimenting digital terrestrial transmissions as well as trading for frequencies and installations. Likewise, the more recent new final National Plan for the allocation of frequencies does not seem to guarantee a plurality of operators in the new digital market.

Gosta [6] describes new requirements for the UHF spectrum set by wireless broadband services and their influence on broadcasting services. The new technological advances such as DVB-T2 standard, H. 264/AVC and H. 265/HEVC algorithm are analysed in order to exam spectrum efficiency achieved by implementation of the new technology. Expectations for the services are taken into account and the amount of digital dividend in terms of broadcasting services and capacity is calculated for chosen type of broadcasting system and coding algorithm.

Ultra High Definition TV (UHDTV) services are being trialled while UHD streaming services have already seen commercial debuts. The amount of data associated with these new services is very high thus extremely efficient video compression tools are required for delivery to the end user. The recently published High Efficiency Video Coding (HEVC) standard promises a new level of compression efficiency, up to 50\% better than its predecessor, Advanced Video Coding (AVC). The greater efficiency in HEVC is obtained at much greater computational cost compared to AVC. A practical encoder must optimise the choice of coding tools and devise strategies to reduce the complexity without affecting the compression efficiency. Naccari et al. [7] describe the results of a study aimed at optimising HEVC encoding for UHDTV content. The study first reviews the available HEVC coding tools to identify the best configuration before developing three new algorithms to further reduce the computational cost. The proposed optimisations can provide an additional $11.5 \%$ encoder speed-up for an average $3.1 \%$ bitrate increase on top of the best encoder configuration. 
The second generation digital video broadcasting system for terrestrial broadcasting (DVB-T2) was designed using a toolbox concept. Compared with its predecessor DVB-T, the new standard introduces many new algorithms and allows for a more flexible parameter configuration. The parameters can be perfectly optimized for each reception scenario, ranging from stationary reception with roof-top aerials, up to portable or mobile reception. However, all countries that have already introduced DVB-T2 mainly focus on stationary reception. In contrast, stationary reception is no relevant option for a potential introduction of DVB-T2 in Germany. Instead, a potential roll-out would focus on the benefits of terrestrial broadcasting compared to satellite and cable, i.e., mobility. Within an extensive field trial in northern Germany, Slimani et al. [8] analyse the performance of the different parameter configurations and new algorithms offered by DVB-T2, e.g., multiple physical layer pipes, rotated constellations, and multiple-input single-output.

Hahm [9] consider HEVC over DVB-T2 systems with a bandwidth of $6 \mathrm{MHz}$, particularly for the terrestrial 4K-UHDTV broadcasting service in the Republic of Korea. The threshold of visibility carrier-to-noise power ratio (ToV $\mathrm{C} / \mathrm{N})$ and the receiver minimum required input level (sensitivity) for satisfying the subjective picture failure (SPF) condition are measured in the laboratory. It is observed, for transmitting $26.37 \mathrm{Mbps}$ data stream correctly, that $\mathrm{ToV} \mathrm{C} / \mathrm{N}$ is $18.8 \mathrm{~dB}$ on average, and the receiver sensitivity is varied from minimum $-84.2 \mathrm{dBm}$ to maximum $-80.0 \mathrm{dBm}$. Based on the results, the receiver noise floor is calculated by $-100 \mathrm{dBm}$ on average.

Spalevic et al. [10] analyse the influence of the basic parameters of the satellite transponder on its capacity. Using DVB Calculator, the influence of modulation formats (QPSK, 8PSK, 16APSK and 32APSK), FEC parameters, Roll-Off factors and Frame Length on Bit Rate and Symbol Rate of satellite transponder are analysed. The analysis shows the Bit Rate for various DVB-S and DVB-S2 standard combinations.

Bruun [11] explores how the television industry is adapting its production culture and professional practises of scheduling to an increasingly non-linear television paradigm, a testing ground where different communicative tools are tried out in a volatile industry. A new television paradigm is being produced from within the multiplatform television organisations themselves in order to adapt to changing viewer habits and the tensions between digital and broadcast television.

\section{DVB-T and DVB-T2 systems}

DVB-T is the most widely adopted and deployed DTT standard. Since its publication in 1997, over 70 countries have deployed DVB-T services and 69 countries have now adopted or deployed DVB-T2. This well-established standard benefits from massive economies of scale and very low receiver prices [13]. DVB-T2 is the world's most advanced digital terrestrial television (DTT) system, which offers more robustness, flexibility and efficiency than any other DTT system, and supports SD, HD and UHD. 
Despite the growing strength of the Internet in the world [12], terrestrial transmission remains an important way of distributing TV program. The main advantage of terrestrial distribution is that it requires minimum investment for viewing - just the terrestrial antenna. But there are possibilities of connecting terrestrial television distribution with Internet, as for example HbbTV, the system that uses Internet for providing additional services for viewers.

\begin{tabular}{|c|c|c|}
\hline & DVB-T & DVB-T2 (new/improved options in bold) \\
\hline FEC & $\begin{array}{l}\text { Convolutional Coding+Reed Solomon } \\
1 / 2,2 / 3,3 / 4,5 / 6,7 / 8\end{array}$ & $\begin{array}{l}\mathrm{LDPC}+\mathrm{BCH} \\
1 / 2, \mathbf{3 / 5}, 2 / 3,3 / 4, \mathbf{4} / \mathbf{5}, 5 / 6\end{array}$ \\
\hline Modes & QPSK, 16QAM, 64QAM & QPSK, 16QAM, 64QAM, 256QAM \\
\hline Guard Interval & $1 / 4,1 / 8,1 / 16,1 / 32$ & $1 / 4,19 / 128,1 / 8,19 / 256,1 / 16,1 / 32,1 / 128$ \\
\hline FFT Size & $2 \mathrm{k}, 8 \mathrm{k}$ & $1 \mathrm{k}, 2 \mathrm{k}, 4 \mathrm{k}, 8 \mathrm{k}, 16 \mathrm{k}, 32 \mathrm{k}$ \\
\hline Scattered Pilots & $8 \%$ of total & $1 \%, 2 \%, 4 \%, 8 \%$ of total \\
\hline Continual Pilots & $2.0 \%$ of total & 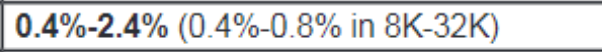 \\
\hline Bandwidth & $6,7,8 \mathrm{MHz}$ & $1.7,5,6,7,8,10 \mathrm{MHz}$ \\
\hline Typical data rate (UK) & $24 \mathrm{Mbit} / \mathrm{s}$ & $40 \mathrm{Mbit} / \mathrm{s}$ \\
\hline Max. data rate $(@ 20 \mathrm{~dB} \mathrm{C/N})$ & $31.7 \mathrm{Mbit} / \mathrm{s}$ (using $8 \mathrm{MHz}$ ) & $45.5 \mathrm{Mbit} / \mathrm{s}$ (using $8 \mathrm{MHz}$ ) \\
\hline Required C/N ratio (@24 Mbit/s) & $16.7 \mathrm{~dB}$ & $10.8 \mathrm{~dB}$ \\
\hline
\end{tabular}

Tab. 1. Comparison between DVB-T and DVB-T2 Source: [13]

Table 1 shows the comparison between DVB-T and DVB-T2 systems. The newer DVB-T2 system offers more different possibilities of FEC, modes, guard intervals and FFT size. But what is most important, it has higher data rate. The maximal data rate is 45.5 Mbit/s for DVB-T2, compared to $31.7 \mathrm{Mbit} / \mathrm{s}$ for DVB-T, which is almost $50 \%$ more. This is the mail advantage and the main reason for transition from DVB-T do DVB-T2 system.

Higher data rate means more TV channels of the same quality and/or better quality of existing TV channels. As every upgrade, from SD to HD, as well as from HD to UHD, requires higher bitrate, DVB-T2 provides here a solution.

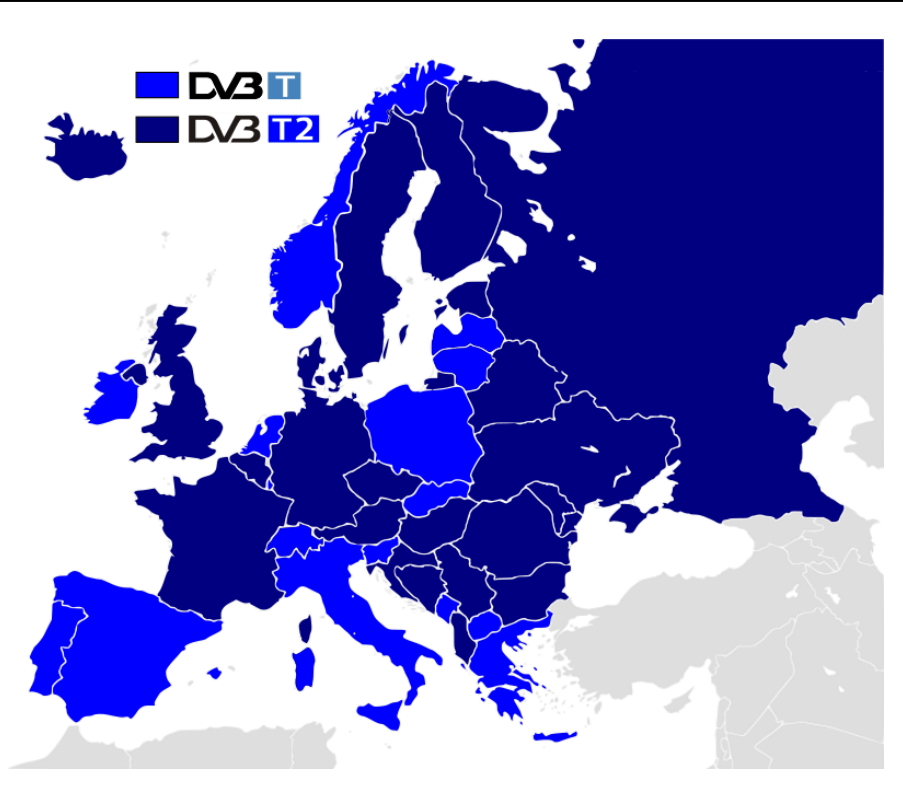

Fig. 1. Digital terrestrial systems in Europe Source: [14] 
Galetic, F.: Economic Rentability of Introducing DVB-T2 HEVC System of Terrest...

Today European countries are using DVB-T or DVB-T2 technology. Of all these countries using DVB-T2, the majority is using h.264, and a smaller part h.265 (HEVC). Two countries from this latter group are Germany and Croatia. This both countries have adopted DVB-T2 HEVC for terrestrial television, which is currently the most efficient way of transmitting terrestrial TV signal.

\section{Efficiency and rentability of terrestrial transmission}

Efficiency can be defined as a level of performance which uses the lowest possible amount of input. In our terms it would be the way of transmitting television with the lowest costs, or with the lowest required bitrate. Accordingly, we are looking for the variant which will save bitrate the most. Rentability means that an action is economically useful, in terms of getting more than invested. Television transmission is rentable if it is creating profit, or in the worst case if it is not creating losses.

Besides the transmission system (DVB-T or DVB-T2), the most important factor for rentability of transmission is the compression system. Starting form h.262 system (called also MPEG 2), over h.264 system (called also AVC), to h.265 system (called also HEVC), the compression development is progressing very fast. Today most European countries are using h.264 system and some of them are switching (or already have switched) to h.265 system.

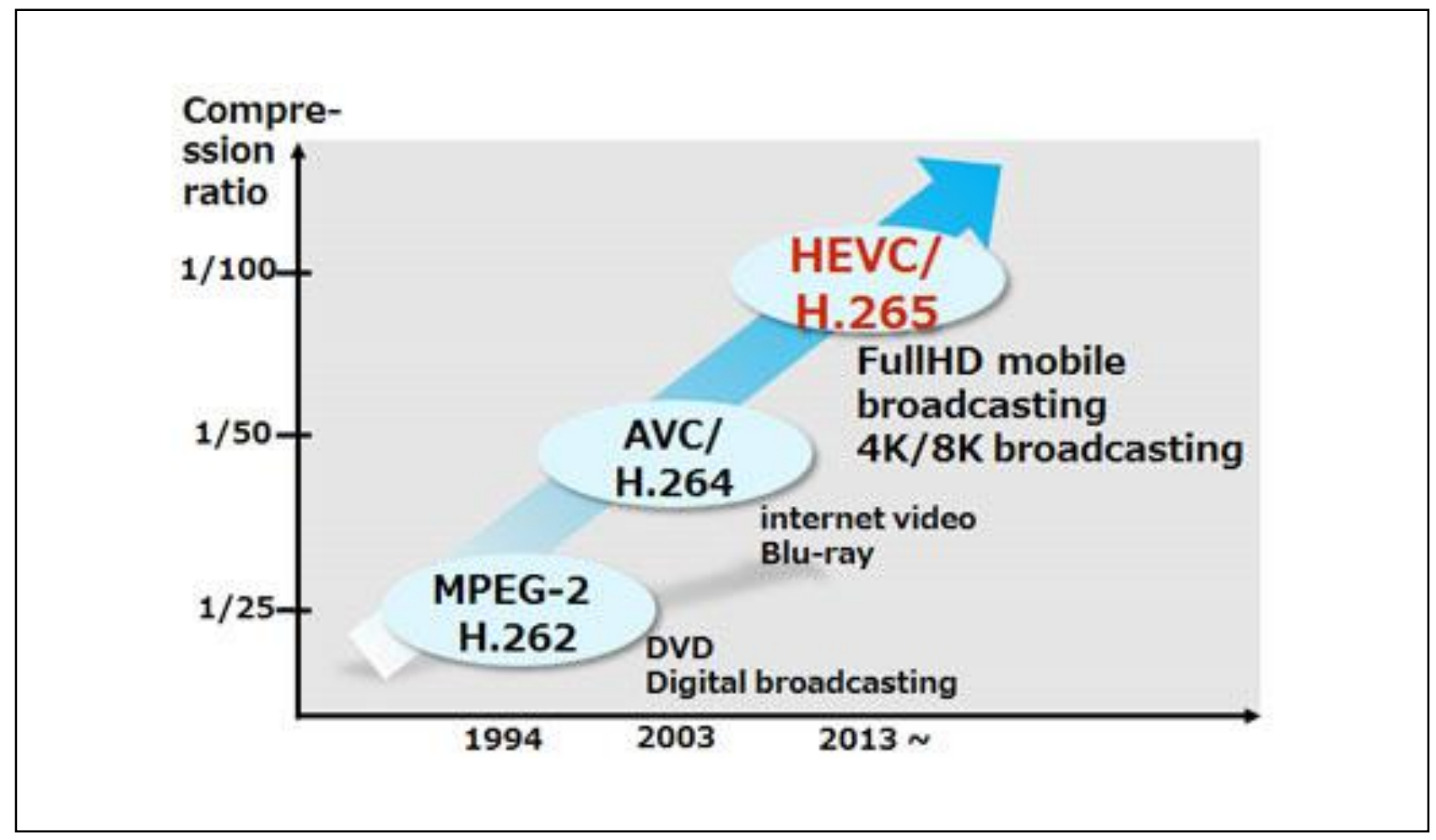

Fig. 2. Development of compression systems for TV broadcasting Source: [15]

The main difference between these three compression systems it their efficiency. AVC saves about $50 \%$ of bitrate compared to MPEG-2, and HEVC saves about $50 \%$ of bitrate compared to AVC. This means that HEVC needs only 25 of bitrate used by 
MPEG-2 for the same data flow. This is important because television channels are using better resolution and better resolution needs higher bitrate. This progress of compression systems enables the development of HD and UHD TV channels even without increasing the data flow requirement.

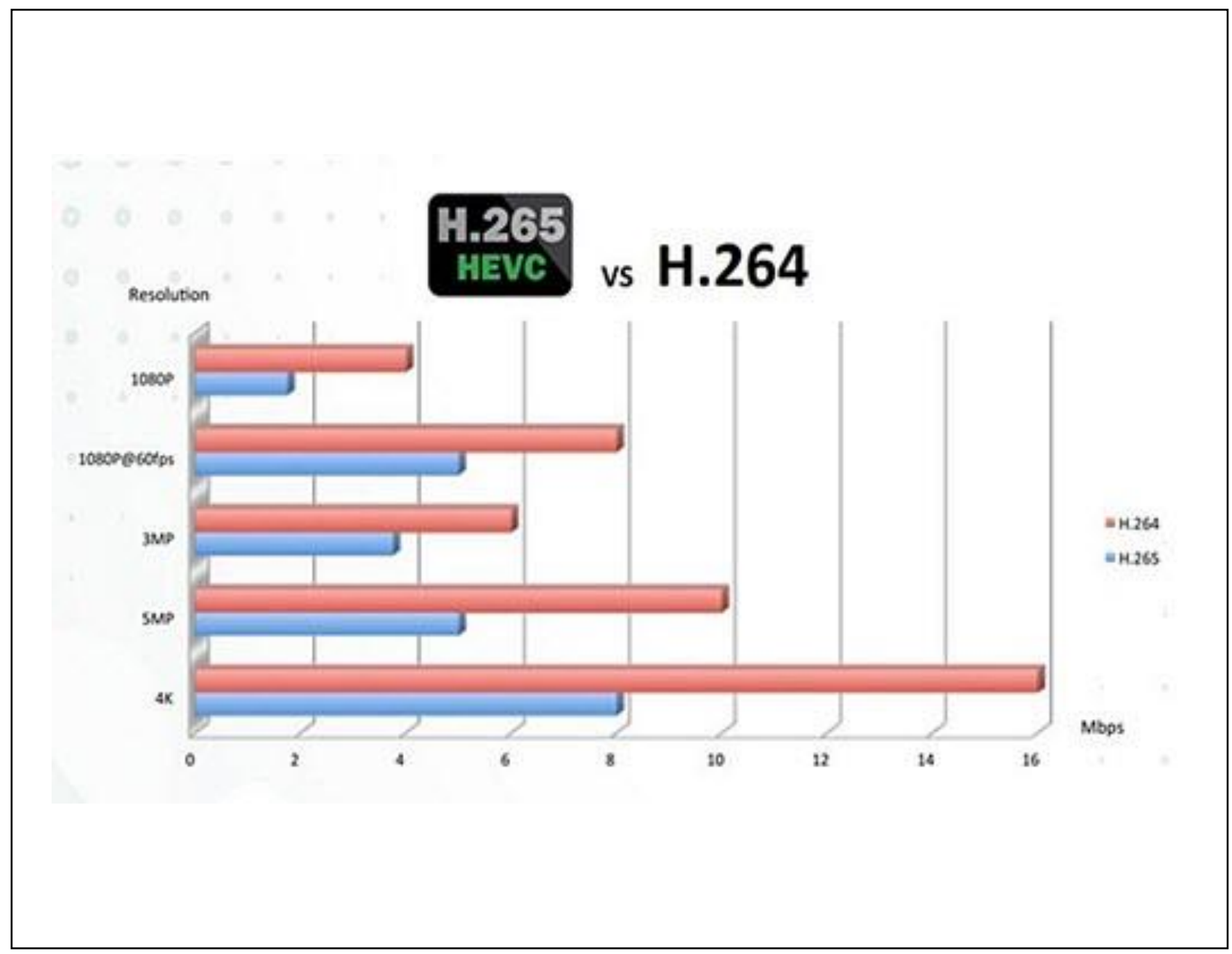

Fig. 3. Differences between h.264 and h.265 systems Source: [16]

Figure 3 shows the differences between h.264 and h.265 in the terms of compression efficiency. The newer h.265 or HEVC system doubles the coding efficiency compared to h.264 system. This means that HEVC saves about $50 \%$ of the bitrate at the same quality of coding. This is more important for higher resolutions, as for example $4 \mathrm{~K}$, which needs about $8 \mathrm{Mbit} / \mathrm{s}$ instead of $16 \mathrm{Mbit} / \mathrm{s}$ using HEVC.

As already mentioned in the Introduction, digital television was at the beginning SDTV, then HDTV, and today there is Ultra High Definition (UHD) television, which is also known as $4 \mathrm{~K}$ (currently there is also $8 \mathrm{~K}$, but still not in the regular use). Standard definition television (SDTV) was the first and the most widely used system of television transmitting in digital television. Today high definition television (HDTV) is practically a standard for television broadcasting, and UHD is still very rare, especially in terrestrial networks. 


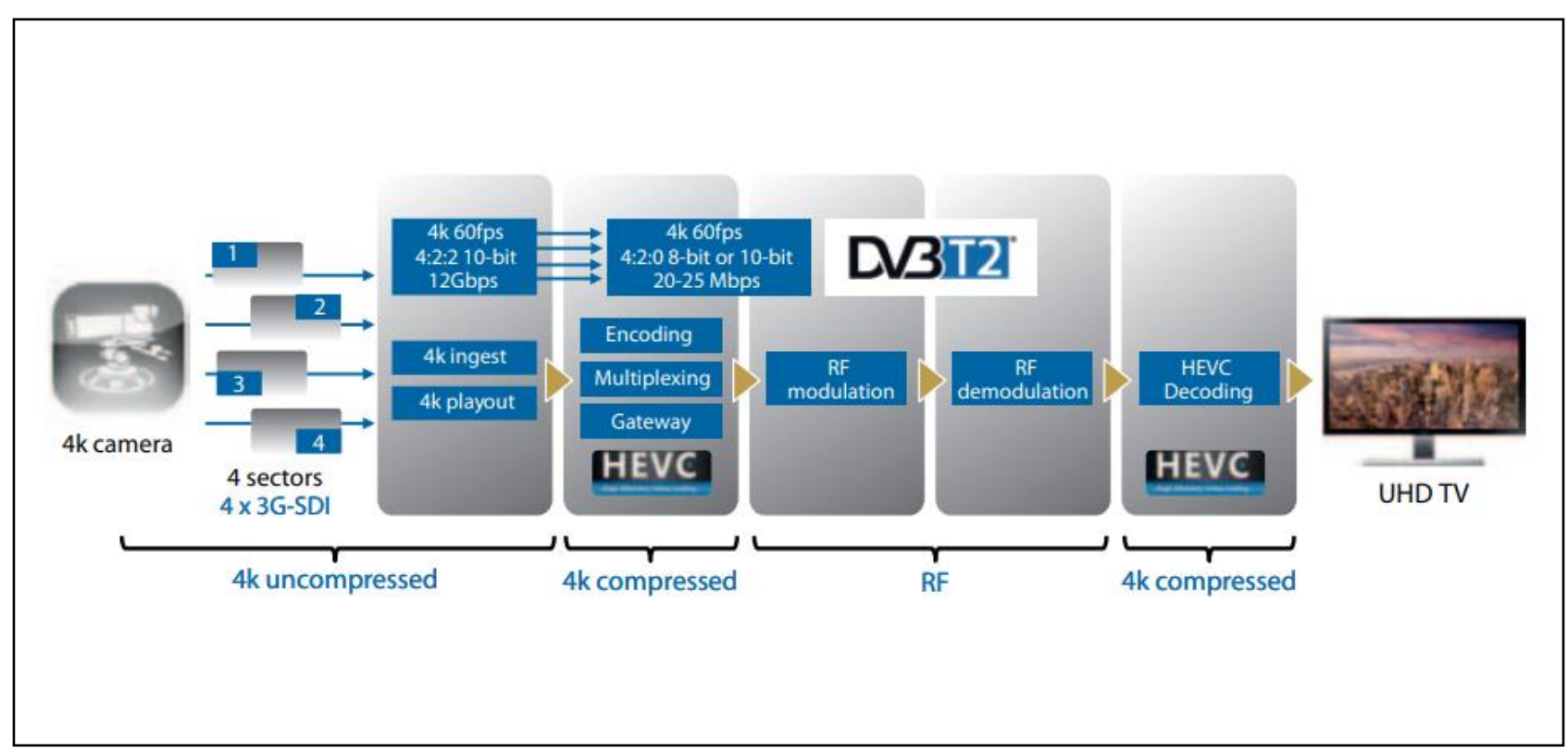

Fig. 4. Example of using HEVC in DVB-T2 for transmitting UHD (4K) TV channel Source: [17]

Figure 4 shows the example of transmitting UHD TV channel $(4 \mathrm{~K})$ in the terrestrial network DVB-T2, using HEVC. The uncompressed input in $4 \mathrm{~K}$ format first has to be compressed and encoded using HEVC. Then after RF modulation and RF demodulation, the signal gets uncompressed using HEVC decoding, and finally the output of this process is UHD TV picture.

The resolution of UHD (4K) channels is 3840x2160, which means that it has 20 times more pixels than SD channel. Accordingly, on the same technology 20 times higher bitrate is required. But the technological progress used in DVB-T2 HEVC compared to DVB-T MPEG-2 enables only 5 times higher bitrate. This is the best example of how efficient is DVB-T2 HEVC system.

\section{Terrestrial transmission technology in Germany and Croatia}

The digital terrestrial television in Germany started in 2003 and in 2006 the whole country was covered by digital signal. The technology was DVB-T MPEG-2 (or h.262), which is the less efficient variant of digital television. In 2016 Germany started a gradual switch from DVB-T do DVB-T2. The new technology is DVB-T2 HEVC, which is currently the most efficient technology in use.

Today German terrestrial TV network transmits 20 public and 24 commercial TV channels, all in HD quality. Public channels are free-to-air, while commercial channels are encrypted. They are part of Freenet-TV package, which cost $6.81 €$ per month.

The first digital television signal in Croatia started in 2002, bit the whole process of digitalisation ended in 2010. The technology used was DVB-T MPEG-2 (h.262), which is the same as the German one. In 2019 Croatia started the experimental 
broadcasting of DVB-T2 HEVC, and the plan was to switch completely to the new system till summer 2020. But due to the coronavirus crisis, this deadline was moved to the end of 2020.

In Croatian DVB-T2 network are planned 4 public and 7 private TV channels, all in HD quality. Additionally, there are local and regional channels in every digital region. All these channels are free-to-air.

Comparing Germany and Croatia, it is obvious that German nationwide TV market has much larger number of TV channels (44 compared to 11). According to that, German switch from DVB-T to DVB-T2 HEVC was much more necessary, than Croatian one. At this moment, Croatian terrestrial TV network has additional capacities for potential new TV channels.

Both Germany and Croatia are using DVB-T2 HEVC system in terrestrial television transmission. Also both countries were using DVB-T MPEG-2 system. This system is efficient, but is it rentable? Transmitting over 40 channels in this efficient system should be rentable, but 11 channels are too less for such an investment. Probably in the future this number of channels will also grow in Croatia.

\section{Conclusion}

This paper presented the newest technology used for terrestrial television transmission-DVB-T2 HEVC. Starting with the literature overview, the practical part of the analysis showed different technologies and main differences between them.

The development of digital terrestrial television started with DVB-T system, and later we got next generation under the name DVB-T2. Besides the transmission system, it is also important which compression system is used. The development from the oldest MPEG-2 system, over AVC system, to HEVC system shows significant savings in bitrates necessary for transmitting.

The most advantageous system for terrestrial transmission, DVB-T2 HEVC, is today used in Germany and in Croatia. Also some other countries are considering the adoption of such systems. Its main advantage is the efficiency, and consequently the rentability of terrestrial television transmission. At the nationwide level, Germany is today transmitting $44 \mathrm{TV}$ channels, and Croatia $11 \mathrm{TV}$ channels. In the future we can expect DVB-T2 HEVC technology to spread further to other countries.

For further research it would be interested to wait other countries to adopt DVB-T2 HEVC system, and to compare their terrestrial TV market before and after this switch. On German TV market the number of channels in terrestrial network went up, while in Croatia it remained the same, but all channels are now transmitted in HD quality. 
Galetic, F.: Economic Rentability of Introducing DVB-T2 HEVC System of Terrest...

\section{References}

Kruger, L.G.; Guerrero, P.F. (2002) Digital Television, Novinka, New York Meron P. (2003) Next Generation SDTV \& HDTV Distribution System, Scopus Network Technologies, Israel

Iglesias, M.J.F.; Sabucedo, L.M.A. (2010) From Analog to Digital Television; Strategies to Promote Rapid Adaptation and Awareness, Journal of Universal Computer Science, Volume: 16 Issue: 8, pages: 1056-1074

Murphy, K. (2013) Digital television policy in Ireland: From inception to analogue switch off, International Journal of Digital Television, Volume: 4 Issue: 2, pages: 125139

Brevini, B.; Fanucci, F. (2013) Digital television in Italy: From analogue to digital duopoly?, , International Journal of Digital Television, Volume: 4 Issue: 1, pages: 7 19

Gosta, M. (2014) Spectrum efficiency achieved by the implementation of DVB-T2 with H.264/AVC and H.265/HEVC, 56th ELMAR International Symposium, Zadar, Croatia

Naccari, M.; Gabriellini, A.; Mrak, M.; Blasi, S.G.; Zupancic, I.; Izquierdo, E. (2015) HEVC Coding Optimisation for Ultra High Definition Television Services, Picture Coding Symposium (PCS), Cairns, Australia

Slimani, M.; Robert, J.; Schlegel, P.; Reimers, U.H.; Burow, R.; Kattanek, F.; Pfeffer, R.; Stadelmeier, L. (2015) Results of the DVB-T2 Field Trial in Germany, IEEE Transactions on Broadcasting, Volume: 61 Issue: 2, Pages: 177-194

Hahm, S. (2016) Laboratory Measurement to Provide Threshold of Visibility for Terrestrial 4K-UHDTV Broadcasting based on HEVC over DVB-T2, Journal of Broadcast Engineering, Volume: 21 Issue: 4, Pages: 506-514

Spalevic, P.L.; Jaksic, B.S.; Milovanovic, I.; Veinovic, M.; Petrovic, M.B. (2017) Influence of the Parameters of the DVB-S/S2 Standards on the Capacity of a Satellite Transponder, 13th International Conference on Advanced Technologies, Systems and Services in Telecommunications (TELSIKS), Nis, Serbia

Bruun, H. (2019) Re-scheduling Television in the Digital Era, Routledge, London

Petcu, D.M.; Gherhes, V.; David, I.; Suciu, S. F. (2010) Globalisation, Internet and Digital Divide, Proceedings of the 21st International DAAAM Symposium "Intelligent Manufacturing \& Automation", Volume 21, No.1

DVB (2015) 2nd Generation Terrestrial - The World's Most Advanced Digital Terrestrial TV System, DVB Fact Sheet

https://en.wikipedia.org/wiki/DVB-

T2\#/media/File:Harta_r\%C4\%83sp\%C3\%A2ndirii_DVB-

T_T2_\%C3\%AEn_Europa.svg

https://www.any-video-converter.com/h265-converter.php https://www.macxdvd.com/mac-dvd-video-converter-how-to/h265-vs-h264.htm

DVB (2014) DVB Scene, Issue No. 44, DVB Project Office 